\title{
El músculo negado. Placer artesano y relaciones socio-afectivas en el culturismo femenino
}

Muscle denied. Craft pleasure and socio-emotional relationships in female bodybuilding

\author{
Mario Jordi Sánchez \\ Universidad Pablo de Olavide. Sevilla (España) \\ amjordi@upo.es
}

\author{
CUERPOS, SEXUALIDADES Y PODER \\ MONOGRÁFICO COORDINADO POR JOSÉ MARÍA VALCUENDE. Universidad Pablo de Olavide (Sevilla).
}

\begin{abstract}
RESUMEN
A partir de una investigación cualitativa basada en observación participante y entrevistas en profundidad, en este artículo se analizan las experiencias corporeizadas de mujeres en el ámbito del culturismo. En primer lugar, se debaten algunas implicaciones asociadas al uso de la teoría subcultural en este ámbito. En segundo lugar, se aplican los conceptos de ascetismo y artesanía al culturismo femenino. Finalmente, se analizan las relaciones socioafectivas de las mujeres culturistas en relación con sus posibilidades creativas y regenerativas. Como aportación, se alude al re-nacimiento de las mujeres culturistas dentro de la experiencia fenomenológica de habitar un cuerpo, que se vincula con su experiencia de placer artesano en el gimnasio.
\end{abstract}

ABSTRAC T

Drawing from participant observation and in-depth interviews, we evaluate in this paper bodily experiences of female bodybuilders. Firstly, we debate some implications associated with the use of subcultural theory in this area. Secondly, we apply the concepts of asceticism and craftsmanship to the field of women's bodybuilding. Finally, we analyse the socio-affective relations of these female bodybuilders in relation to their creative and regenerative potential. The findings reflects the re-birth of female bodybuilders within the phenomenological experience of inhabiting a body which is linked to their experience of pleasure in the gym.

PALABRAS CLAVE

ascetismo | culturismo | artesanía | gimnasio | placer | transgresión de género

KEYWORDS

asceticism | bodybuilding | craftsmanship | gym | pleasure | gender-transgression

\section{Introducción}

La presencia del músculo en el cuerpo de la mujer presenta en nuestra sociedad no pocas contradicciones y paradojas que pueden vislumbrarse claramente en las prácticas deportivas, de las que el culturismo presenta un caso enormemente sugerente. Se trata este de un deporte fundamentado en el provecho de la imagen, no en el desempeño concretado en una marca, en un tiempo o en la consecución del levantamiento de un peso, como sí ocurre en su deporte hermano, la halterofilia. Su objetivo es una determinada configuración corporal, que se considera alcanzada delante del espejo o ante los ojos de otros/as. Cualquier persona (o más específicamente, monitores, entrenadores o jueces en las variantes más desarrolladas y/o de competición) se puede habilitar como tasador del resultado alcanzado. El cuerpo supera cualquier atisbo de neutralidad y se convierte así en el centro de atención, en la medida del nivel de desarrollo alcanzado, en el objeto de las comparaciones con otros cuerpos.

Este carácter interpelador que desempeña el cuerpo se eleva hasta sus cotas máximas en el caso del culturismo femenino, a lo que contribuyen las construcciones sociales de género dominantes en la sociedad y sus correspondientes rigideces. En nuestro país, tales rigideces han llevado además a que la categoría deportiva del culturismo femenino haya entrado en declive desde los años 90 , hasta llegar hoy a su práctica desaparición en cuanto a competiciones de carácter nacional. (1) Así, la idea de mujeres musculadas desafiando el límite de las normas sociales del momento no sólo ha causado escándalo social, sino que ha abonado el terreno para adoptar posiciones ideológicas, epistemológicas o académicas encontradas. En el caso de las Ciencias Sociales, la problemática asociación entre muscularidad y feminidad ha 
proporcionado jugosas producciones (Lowe 1998, Connel 2000). De forma general, el argumento más recurrente en la literatura sobre la práctica deportiva de las mujeres musculadas pone de relieve toda una serie de posicionamientos transgresores y/o anuentes frente a las normas de género hegemónicas. Pueden destacarse aquí aquellas aproximaciones que, desde la ciencia social feminista o, más recientemente, desde posiciones cercanas a la teoría queer (Schipert 2007) han evidenciado las implicaciones empoderadoras de la práctica del culturismo por las mujeres (Brace-Govan 2004, Grogan y otros 2004, Kane 1995, Shea 2001), apuntando a la conquista de un poder físico secularmente negado en términos que van desde la liberación física a la autorrealización o al autocumplimiento (Castelnuovo y Guthrie 1998, RothBassow 2004, y Roussel y Griffet 2000).

Buena parte de estos enfoques y miradas se incardinan dentro del prisma de lo que ha sido considerado como desviación con respecto a las normas de género, desde un enfoque interaccionista apoyado en la figura conceptual del orden de interacción de Goffman (1963 y 1983) u otras análogas. Así, partiendo de la idea de "género transgresor" de Bornstein (1995), Schilling y Bunsel (2009: 148) refieren que "la mujer culturista es considerada escandalosa a juicio de los 'normales' debido a que rechaza los roles, costumbres, técnicas corporales y apariencias relativamente pasivos asociados con el aprendizaje en la feminidad occidental (...) y están adoptando modos masculinos de apariencia física, comportamiento, acción, experiencia y consumo". La idea de conducta desviada resulta ampliada por otros autores cuando resaltan su carácter de acción colectiva, en la que se dan cita una diversidad de agentes y contextos, de los que las mujeres culturistas serían solo parte, albergando un carácter dinámico y heteronormativo (ChananieHill, McGrath y Stoll 2012). Como refieren Hughes y Coakley (1991: 308), en general, la conducta desviada de estas atletas no se dirige automáticamente al rechazo de los valores dominantes, sino que puede implicar una "sobre-aceptación" de las normas explícitas o implícitas del deporte, tales como la dedicación, la distinción, la búsqueda de éxito y la aceptación de obstáculos, riesgos o lesiones. Así, puede encontrarse que la búsqueda del éxito de claras implicaciones productivistas, inherentes al deporte de competición en general, y al culturismo en particular (Klein 1992), propicia cierto reforzamiento en la marginación de las mujeres, como proponen Rousell y Griffet (2000: 134). Estas autoras se apoyan en una interpretación ampliada del concepto marxiano de alienación, en términos de "adhesión total" a la disciplina (Rousell y Griffet 2000: 131), a la que añaden, no obstante, ciertas, aunque acotadas, implicaciones emancipadoras en términos de agencia por parte de las mujeres culturistas.

Pese al desarrollo de este campo de estudio, particularmente desde aportaciones anglosajonas, consideramos que existen líneas interpretativas que precisan ahondarse y en las cuales podemos situar esta contribución. En particular, existe una escasez de investigaciones sobre cuestiones fenomenológicas que procuren, como ya subrayan Schilling y Bunsel (2009: 143), un acercamiento a este universo en términos de análisis de experiencias vitales genuinas, tejidas desde el conocimiento en profundidad de sus expectativas, motivaciones y percepciones corporeizadas, incluyendo por tanto "la experiencia vivida de cómo se construye el físico de la mujer culturista o de cómo se recibe su 'asalto' a las normas convencionales de la apariencia femenina, tanto dentro como fuera del gimnasio" (Schilling y Bunsel 2009: 143). Una aproximación que, como proponen Roussel y otros (2010: 108), sitúa nuestro objetivo investigador, no tanto captando la experiencia de las mujeres culturistas a través de la intuición o la reflexión, sino a través de un enfoque sociológico in-corporado. Es decir, a través de una agenda de investigación que asuma el contacto sostenido con los cuerpos vividos, sentidos y generizados en los contextos de la vida cotidiana.

De este modo, el empeño de apostar por tal acercamiento etnográfico in-corporado de resonancias interaccionistas nos lleva, en primer término, al campo de las trayectorias vitales de las mujeres culturistas, del que optamos en un segundo nivel de concreción por intentar presentar algunas preguntas y respuestas sobre la belleza, el placer y las relaciones socioafectivas. El empeño de evidenciar las respuestas creativas de estas mujeres a la hora de construir sus cuerpos y de vivir sus relaciones nos llevará, superando rígidas concepciones dicotómicas de sexo-género y fuertes estigmas asociados a este campo, a referimos al culturismo como espacio de goce, situando el campo de las relaciones socioafectivas y del placer en el gimnasio, es decir, parafraseando a Monaghan (2001: 334), nos centramos en "los placeres de representación y sensuales que los entusiastas del músculo derivan de su dinámico mundo físico".

\section{Metodología}


Este empeño investigador ha implicado, en términos metodológicos, una aproximación etnográfica fundamentada en el trabajo de campo durante cinco años. (2) Ello se ha concretado en la observación participante realizada en un total de tres gimnasios localizados en la ciudad de Sevilla, con estancias superiores a los dos años en dos de ellos, lo que ha llevado aparejado la práctica de este deporte a nivel amateur por parte del investigador, con el seguimiento de pautas de entrenamiento y de orientaciones dietéticas básicas. Durante este trabajo de campo, aparte de las conversaciones informales y anotaciones registradas en notas de campo, se han realizado un total de 46 entrevistas a personas vinculadas a este deporte, desglosadas del siguiente modo: 18 a hombres culturistas, 10 a mujeres culturistas, 8 a familiares de culturistas de ambos sexos, 6 a monitores y entrenadores de salas de musculación y 4 a jueces y personal federativo. Con todo ello, se ha pretendido incluir a los agentes e instancias más significativos de este deporte dentro del territorio español, con énfasis en Andalucía, territorio donde además se concentra en la actualidad la proporción más significativa de practicantes y competidores de este deporte. Todo lo cual ha supuesto incorporar a más mujeres de forma numérica de las que, en proporción, practican el culturismo (a lo que se añade el referido declive de este deporte en su vertiente femenina) (3) e incluir una diversidad de perfiles en cuanto a edad, años de dedicación a este deporte y vinculación personal, profesional o técnica.

Algunas dificultades etnográficas han adquirido cierta relevancia, como es el caso de las restricciones de acceso a algunos contextos de intimidad, el alejamiento de algunos espacios de sociabilidad o la elipsis de la experiencia directa en temas más comprometidos como el uso de sustancias anabolizantes. Por otro lado, nos hemos aproximado a otras esferas de análisis y observación como la institucional (los estamentos federativos dentro del culturismo, incluyendo revisión de la normativa y del discurso de los jueces y personal federativo), o la relativa a las relaciones sociofamiliares (incorporando entrevistas y contactos informales con personas del entorno familiar) a lo que se superpone la visión de los compañeros varones, tanto en entrenamientos como en competiciones. El trabajo de campo se ha completado con la revisión de abundante material formativo e informativo relativo al entrenamiento del culturismo (nutrición y suplementación dietética, sistemas de entrenamiento) y a la asistencia a eventos competitivos a escala local y regional.

\section{Resultados}

\subsection{Culturismo: estigmas y culturalismo}

Junto al referido carácter interpelante del culturismo sale al paso su imagen pública, fuertemente estigmatizada y estereotipada. ¿Qué sabemos del culturismo más allá de lo que nos dicen las continuas noticias sobre sus excesos? Socialmente, en buena medida, no sería más que un compendio de algunas contradicciones y sinsentidos de nuestra sociedad: obsesión por la imagen física, búsqueda de resultados con el mínimo esfuerzo, atadura a las modas, medicalización, materialismo, individualismo, consumismo y cierta estulticia, en la medida en que se supone que la dedicación excesiva al ejercicio físico se detrae del mental. Individualmente, sería atribuible a sus practicantes: negacionismo, superficialidad, baja autoestima, escaso equilibrio emocional, comportamientos obsesivos, conducta antisocial, cortoplacismo, superficialidad, manipulabilidad e inmadurez y cortedad mental. Su rechazo social, mayor aún para las mujeres, apunta al carácter "extremo" o "abyecto" (como sugiere Butler 2002: 20) atribuido a los cuerpos culturistas. Pese al culto al cuerpo y al deporte en nuestra sociedad, el culturista sería una especie de sucedáneo de deportista, cercano a la trampa de las drogas, o a algo que causa aún más escándalo, al doping.

Al culturismo se le conoce pues por su caricatura, a lo que sin duda contribuye el desconocimiento o el prejuicio más repetido. No sorprende que los/as culturistas reaccionen airadamente frente a este estigma, y más aún cuando, en los últimos tiempos, el compendio de todos los males del culturismo resulte ser una enfermedad como la vigorexia. Una enfermedad, por cierto, cuya mera existencia aún está en discusión por tratarse más de un síndrome de filiación cultural que de un trastorno con cierta entidad objetivable, pese al impulso que viene recibiendo por parte de los poderes biomédicos (Jordi 2005). Una enfermedad, pues, en fase de construcción sociopolítica que en este caso ha pasado a convertirse rápidamente en adjetivo calificativo: ser culturista es ser vigoréxico.

Lo que en nuestro trabajo de campo hemos encontrado supera, como cabe esperar, este panorama 
sobresimplificado y estigmatizador. En el deporte del culturismo conviven la cultura de la inmediatez con la del deporte que da sus frutos a largo plazo, las preocupaciones estéticas con las de salud, el exhibicionismo con la introversión, el narcisismo con el recato, la obsesión con la despreocupación, la necesidad de reconocimiento con las ansias de autosuperación, el complejo con la virtud... Coexisten el culturismo aficionado con el competidor, el culturismo contrario al uso de sustancias dopantes con el que las usa... Si hubiera que primar entre las posibles diferenciaciones discursivas que se realizan dentro del campo, podría destacarse la que se basa en las tendencias superficiales y perentorias frente a la estabilidad, es decir: culturismo experto o comprometido frente al neófito, superficial. En este sentido, es preciso advertir aquí que el culturismo, conforme se hace tal trabajo experto, supone una reconstrucción o moldeado corporal que comporta una gran dificultad en su ejecución, porque los efectos ni son instantáneos ni son fácilmente predecibles, pues cambian según un gran número de variables (entrenamiento, dieta, genética, descanso, suplementación...). Al conocimiento de estos extremos se exige, en un nivel de competición, la ineludible observación de criterios de simetría, volumen y definición, variables por sexos y categorías, que imponen un alto sentido estético, elevadas dosis de objetividad y equilibrio mental y emocional. Por todo ello, se impone tanto la experimentación (fundamentada en la experiencia, en el estudio y en la documentación) como la necesidad de una "mirada externa" que complemente lo que el afán perfeccionista no termina de ver.

Más allá del espacio de complicidad que podamos haber establecido con nuestro objeto de estudio (véase una interesante reflexión sobre este tema en Marcos 2008: 6-8), no es nuestro objeto al presentar estas evidencias el desmontar todo el referido paquete de estereotipos y estigmas, sino simplemente presentarlos grosso modo para así hacer una alusión a la complejidad y diversidad del campo y perfilar así el contexto sobre el que el culturismo femenino se desarrolla. Y también, en consecuencia, para evidenciar que la ciencia social, como parte de la sociedad que es, no ha sabido abstraerse plenamente de tales estereotipos y estigmas: cualquier revisión con un mínimo de profundidad sobre la atención que las ciencias sociales han prestado a este universo encuentra dos líneas investigadoras recurrentes. La primera, la preocupación desde la psicología por los trastornos y excesos individuales (drogodependencias, adicción al ejercicio y otros desequilibrios, sintetizados en la referida vigorexia); la segunda, fundamentada en el estigma de los/as culturistas como microgrupo social homogéneo, anclada en las interpretaciones culturalistas. Es este un reto asumido de diferentes modos en la bibliografía disponible sobre este tema que, no por casualidad, ha girado en buena parte en torno al concepto de subcultura. Así, Rossel y Griffet (2000: 131) dedican una detallada revisión bibliográfica a su aplicación al mundo del culturismo, destacando la obra de Alan M. Klein (1993) Little Big Men. Bodybuilding Subculture and Gender Construction. En este tipo de aproximaciones, como en tantos otros ámbitos en los que el concepto de cultura ha buscado amparo explicativo, el problema no radica tanto en el concepto de cultura en sí como en la necesidad de superar sus posibles implicaciones inmovilistas, esencialistas o generalizadoras. Esto es así porque, así empleado, dicho concepto no remite tanto a una posición de subordinación con respecto a la cultura dominante, como a una (pretendida) especificidad cultural. Lo subcultural no es en este caso lo minoritario, sino lo raro, lo exótico. Para construir una subcultura se refiere a un contenido cultural: unas pautas de comportamiento comunes, un universo simbólico, una estructura de relaciones sociales que le es propia... Para ello, es preciso obviar las diferencias, las disensiones o la heterogeneidad. Para redondear esta cosificación hay que generar implicación, posicionamiento, es fundamental subrayar la identificación racional con sentimiento, afinidad. Y aquí el culturismo, por su especial carácter fuertemente interpelante, cobra un papel fundamental, contribuyendo a un posicionamiento entre la adhesión y el rechazo. La construcción de la subcultura del culturismo puede en este sentido ser deudora del referido universo estigmático y simplificado que la impregna, algo que puede aún acrecentarse para el caso del culturismo femenino, fuertemente afectado por la rigidez de normas de género.

A efectos prácticos, lo anterior se traduce en la necesidad de reconocer la complejidad y dinamicidad en la estructuración de este campo en el sentido más bourdieuano del término. Cobran aquí también importancia las categorías que se construyen desde dentro del campo por sus propios protagonistas, como hemos referido. En todos los casos, un argumento destacado es la línea trazada por la experiencia y la capacidad adquirida en términos de capital social, no sólo de rendimiento físico, sino por la cantidad y calidad de información que se posee. En la práctica, si a quien le pide consulta cualquier/a usuario/a de un gimnasio es "al que parece más fuerte", lo más común en cualquier manual realizado por un exculturistas es encontrarnos que este acompañe no sólo su currículum y su experiencia en la solapa del libro, sino una buena fotografía de su cuerpo musculado de sus "años de gloria". Que el culturismo es un deporte de estética, pero sobre todo, de información y de experiencia lo evidencia también la efervescencia de sus producciones informativas al gran público: un total de seis revistas especializadas pueden comprarse en los kioscos en 
nuestro país en la actualidad, algo que mantienen pocos deportes, ni siquiera masivos. A esto se le suma una buena cantidad de páginas webs especializadas que brindan al aficionado una gran cantidad de información sobre los últimos adelantos en nutrición y, en menor medida, entrenamiento.

\subsection{El goce artesano en el culturismo femenino}

Pese a los recientes cambios en nuestra sociedad, una mujer en un gimnasio de musculación es, en muchas facetas, una rara avis. Para ello es preciso atender a la etnografía sobre el terreno, en lo tocante a las condiciones técnicas en que se desarrolla la actividad y a las configuraciones sociales resultantes. Simplificando algo que en la práctica resulta mucho más complejo, la mecanizada reconstrucción del cuerpo en el gimnasio sigue una división funcional en dos tipos de aparatos vinculados al trabajo que, predominantemente pero no exclusivamente, se realiza en ellos: los aparatos y máquinas aeróbicos (popularmente conocidos como de cardio, porque en ellos suelen realizarse ejercicios de entrenamiento cardiovascular de baja intensidad y ejecución ininterrumpida que conducen al adelgazamiento o al entrenamiento de resistencia) y los de tipo anaeróbico (vinculados a ejercicios de alta intensidad y corta duración, realizados con descansos, dirigidos al entrenamiento de fuerza y al crecimiento muscular). Las mujeres copan el primer grupo, lo que comúnmente se llama parte aeróbica del gimnasio (cintas, elípticas, bicicletas...) estando el uso del resto de aparatos "de fuerza", incluidos pesas y mancuernas, claramente masculinizado, salvo en el caso de aquellos instrumentos que se dirigen a trabajar muslos, glúteos y caderas. Resultante esto último de la predominante división generizada del trabajo muscular, resumido en la sentencia: "los hombres entrenan de cintura para arriba y las mujeres de cintura para abajo".

Dicho esto, las dificultades para una mujer que quiera desenvolverse en un gimnasio "como un hombre" son claras, y más contundentes cuando aquella se encuentra en su fase inicial, es decir, en los primeros meses y a veces años de entrenamiento. Por supuesto que la reciente proliferación de las cadenas de gimnasios femeninas y su ambiente amable y especializadamente aeróbico confirman este punto. Existen también razones de afinidad social o exclusión simbólica (los comentarios masculinizados, las demostraciones de hombría a través del ejercicio de la fuerza...), pero estos son solo una parte pequeña de las posibles explicaciones. Solo el conocimiento experto de las claves de funcionamiento técnico en este escenario nos ayuda a comprender esta segregación de hecho que vive la mujer en el gimnasio, que es común en cierta medida a la que vive el neófito varón en sus primeros meses. Ello pasa por conocer los sistemas de entrenamiento con pesas que exigen una rutina prefijada de trabajo por grupos musculares distintos cada día, el necesario apoyo de compañeros de gimnasio (habitualmente una pareja de similar desarrollo muscular) y un considerable dominio técnico de los movimientos y de los aparatos.

Como cualquier aprendiz que entra en un taller por vez primera, una de las primeras cosas que aprende el neófito/a en el gimnasio es a saber estar en él, no dificultando el trabajo de otros. Si el monitor de sala (habitualmente suele ser un varón) no lo guía de continuo, lo más normal es que en sus comienzos la persona que se inicia entorpezca el trabajo de otros sin saber que lo está haciendo: alargando el tiempo de recuperación entre series de otro usuario del gimnasio cuando ocupa el aparato en la que este ya se encontraba trabajando, no sabiendo o no preguntando si una determinada máquina o aparato están siendo usado antes de desmontar o sustituir su peso, etc. En general la reacción ante estas pequeñas faltas del recién llegado es de camaradería y de comprensión porque se recuerda que "todos/as han sido antes principiantes", pero en algunos casos los gestos de fastidio son más que evidentes. Por supuesto que, en menor medida, estos conflictos pueden darse también entre los/as que ya llevan tiempo entrenando, pero no es menos cierto algo que, a primera vista resulta especialmente llamativo: para no molestarse entre ellos/as, los/as culturistas que comparten un horario de entrenamiento ajustan su agenda de trabajo muscular semanal, en una especie de acuerdo tácito, rara vez hablado. Aunque en el gimnasio parezca que "todo el mundo va a la suyo", suele saberse en qué día quiénes son los/as que van a "hacer" piernas, hombros, brazos, pecho o espaldas. Ni que decir tiene que se sabe quién falta y cuando falta, lo cual tendrá consecuencias en el control que se ejerce sobre el entrenamiento de los demás, en su progreso y en sus consecuencias.

Que a una mujer culturista se le trate de forma paternalista por algunos de sus compañeros varones más desarrollados muscularmente, cosa que ocurre en no pocas ocasiones, no significa que necesariamente vean a aquella como a una principiante. Esto es así porque en el culturismo prima el desarrollo muscular como eje de distinción, pero también el grado de conocimiento técnico que se ostenta. Aunque no pocos jóvenes y neófitos olvidan esto, en ocasiones hemos presenciado el trato respetuoso y de reconocimiento 
ante mujeres culturistas experimentadas a las que sus compañeros varones han acudido ante dudas en el sistema de entrenamiento o descanso, 0 ante el camino a seguir en las pautas dietéticas o de suplementación.

Una vez consolidados el saber hacer y el saber estar, la experiencia gozosa en el gimnasio se acrecienta conforme se asienta la práctica en el gimnasio. Esto sólo se entiende si advertimos que, frente a la atribución generalizada de una cultura de la inmediatez o de la frivolidad emerge un deporte que, en sus versiones más estables por su continuidad en la práctica que hemos llamado culturismo experto o comprometido, alberga también un proceso lento de compleja y pensada transformación. Entendemos por ello que este universo presenta claros paralelismos con el ejercicio artesano en la medida en que este exige continuidad, experiencia, conocimiento, sentido estético, renovación y, sobre todo, compromiso. Recordemos que para Richard Sennet (2009: 360), el artesano representa la condición específicamente humana del compromiso, en la medida en que "la actividad corporal repetida y la práctica permiten a este Animal laborans desarrollar la habilidad desde dentro y reconfigurar el mundo material a través de un proceso lento de metamorfosis".

Pero la metamorfosis del artesano culturista es doble: resultado del compromiso continuado con su objeto de trabajo, en este caso su cuerpo, y producto de los cambios en este objeto-sujeto sobre la base de la técnica. Cobra sentido aquí la noción de habitus que a la hora de ilustrar en diferentes sociedades las técnicas del cuerpo nos aporta Mauss (1973: 73), en el sentido de técnicas y razones o lógicas asociadas a prácticas colectivas e individuales. Repetición, continuidad e intencionalidad son argumentos recurrentes en el devenir artesano. Como documentan Roussel y otros (2009: 104), se trata este de un proceso consciente y sentido en cada ejercicio, en cada sesión de entrenamiento, ejercido durante años, en el que la mutación es proyectada, deseada o conseguida. Algo que, para el caso de las mujeres, a medida que les integra en lo que estos autores consideran la "subcultura" de este deporte, les sitúa en medio de la crítica hacia el grado de feminidad que su cuerpo gana o pierde.

En todo caso, el cuerpo del culturista es su herramienta de trabajo, y a la vez su producto, su tarjeta de identificación, su "cara". En el "cuerpo trabajado" se reconocen facciones y expresiones tanto por la persona que los posee como por los que la rodean, lo cual se traduce en satisfacción. Y la satisfacción por el trabajo "bien hecho" se refleja en los testimonios de las mujeres culturistas, que experimentan el placer de sentir sus músculos crecer y comprueban así como su belleza se extiende a lugares no habituales del cuerpo, con expresiones del tipo "Me gusta verme bien, sentirme bien, ver mis hombros definidos, la curva del triceps...", "Nunca imaginé que podía tener en mis manos tanto peso y estar a la vez tan guapa" o "A mí todos los días, las niñas me dicen 'yo quiero estar como tú', con esos brazos, esos abdominales...". El modo en que Roussel y otros (2009: 105) aplican la diferenciación kantiana entre "belleza libre" y "belleza adherida" (sometida esta a juicios no solo de gusto o estéticos, sino también de valor) sitúa a los anteriores testimonios como la contrapartida de aquellos que se emiten desde la descalificación, el desinterés o simplemente el desprecio. Como nos recuerda una de las entrevistadas más mayores: "Claro que te etiquetan... Y con las mujeres ya te digo... Yo, o era camionera o era tortillera o era... Perdona. Yo soy ama de casa y... lo que pasa es que me gusta esto".

Sobrevuela en este tipo de testimonios el esfuerzo por normalizar el propio sentido del gusto, íntimo, personal, ejercido como arma. Aún en los casos, más frecuentes en cuanto el desarrollo muscular de la mujer es más intenso, en los que se produce conflicto familiar o personal por salirse de las normas de género, emergen los discursos en los que se representa esa vivencia de la autosatisfacción, del autorreconocimiento o, simplemente, de una escucha selectiva de aquellos que no complacen a los objetivos propios declarados. De entre las figuras de referencia hacia las que la culturista se ve obligada a elaborar tales discursos de autojustificación destaca la figura de la madre:

"En mi familia... mi padre acepta todo lo que haga siempre, porque sabe que soy una persona muy competitiva conmigo misma... Mis hermanos son deportistas, entonces lo llevan bien. Y mi madre es la que lo lleva peor. Mi madre piensa que estoy estropeando mi cuerpo, que tengo piernas de futbolista, barba de hombre y que me va a salir pelo (ríe). Sí, sí, así... son sus palabras de todos los días, cada vez que me ve. Y me ve poco ¿eh? Pero yo tengo las ideas muy claras de lo que quiero. Escucho más a mi padre que a mi madre..." (mujer culturista, 26 años, 4 de práctica, 2 compitiendo).

“La única opinión así que tenía es cuando venía algunas veces mi madre, cuando venía y me decía: ‘Es 
que eres muy rara, yo no te entiendo'. Y yo le decía: 'Sí mama, es verdad...'. Ya te digo, tampoco le daba muchas explicaciones. Y después como yo no he sido una persona exhibicionista, en el sentido de mostrar mi cuerpo en público ni nada, pues bueno... Mis amigas también lo han llevado siempre bien, porque realmente yo estaba muy fuerte, pero vestida de normal no se ve nada" (mujer culturista, 34 años, 8 de práctica, 2 compitiendo).

La experiencia fenomenológica que, como propone Monaghan (2001) implica "habitar un cuerpo" supone todo un cambio sensorial y sensual. El gimnasio es el lugar de liberación de tensiones y endorfinas. No solo es ver crecer los músculos, también es sentirlos, ser consciente de que existen. La fragmentación y racionalización del cuerpo que conlleva el trabajo del gimnasio tiene como una de sus consecuencias la necesaria toma de conciencia de su localización, su ubicación, su funcionamiento: "Te pasa sobre todo los días que entrenas intensidad. Te sientes cansada, dolorida pero a la vez es sentir que el corazón bombea sangre a tus músculos, que llegan a tus brazos, a tus piernas... te sientes viva, cargada de energía" (mujer culturista, 30 años, 10 de práctica).

Esta vivencia gozosa del dolor, combinada con las restricciones de la dieta y, en menor medida, del descanso, acerca al culturismo a la opción ascética-espartana que sitúa en el músculo el dogma de fe (Jordi 2012: 307). Consagrado a su fin máximo, apartado de la lógica mundana, la vía ascética se convierte en una necesidad y en una marca de distinción. Recordemos aquí las palabras del inspirador trabajo de Loïc Wacquant (2004: 149) cuando se refiere a la vida reglamentada del boxeador, austera y aburrida, "a la manera de los 'grandes ascetas' religiosos":

"El que desea ardientemente ingresar y ascender en el universo pugilístico debe esforzarse para expatriarse del mundo, desentenderse de sus juegos y volverse indiferente a sus tentaciones. Debe prepararse para sacrificar todos los intereses profanos en el altar del ring. Porque sólo a través de una ascesis rigurosa y el secuestro ocupacional prescrito por la ética del 'sacrificio', forjará esas cualidades de dureza, abnegación, perseverancia y rabia controlada necesarias para dominar la dulce ciencia y resistir en el oficio de los golpes".

La delgada frontera entre placer y dolor no puede entenderse en términos estrictamente físicos. Lo agradable de esta sensación proviene también de que el dolor es parte del proceso de construcción, es la anticipación de la ansiada metamorfosis. El cansancio es la certeza del trabajo bien hecho: un/a culturista sonríe cuando tiene agujetas, y lo comenta satisfecho/a y orgulloso/a a sus colegas de gimnasio. La explicación fisiológica, conocida por cualquier atleta, también ayuda: las "temidas" agujetas no son sino roturas musculares, la verdadera antesala para una reconstrucción que, con la nutrición y el descanso correctos, florecerá en el ansiado crecimiento muscular. Quizá uno de los momentos que más puede sorprender al profano en este mundo ocurre cuando escucha los comentarios sobre las agujetas entre los y las culturistas: estos no son de padecimiento, sino de satisfacción por el trabajo bien hecho en el día anterior. Contar que se han tenido serias dificultades para poder sentarse en una silla o en la taza del váter después de la sesión de trabajo de piernas que se realizó hace tres días puede ser motivo de celebración y hasta de admiración. La explicación se vincula en parte con el apego a la dualidad dolor-placer, en parte con la necesidad de socializar el dolor como signo de distinción y en parte con la satisfacción por la certeza del objetivo cumplido, a partir de una constatación sensorial que guía el trabajo diario: para evitar sobrecargas y favorecer el crecimiento muscular cada día se trabaja un grupo muscular distinto, y aquél músculo que duele es el que realmente crece, y es el músculo al que le toca descansar uno o varios días hasta que deje de doler.

En la medida en que "se construye un nuevo cuerpo", no es casual que autores como Frueh (2001) o Monaghan (2001) se refieran a este proceso en términos de "transformación sensual" e incluso de "renacimiento". $Y$ esto es así porque este empeño artesano tiene implicaciones más regeneradoras que reproductivas, como nos ilustra el caso de una de nuestras informantes, Lucía. Se trata de una culturista madrileña de 37 años que, separada de su pareja y sin hijos, consagra la mayor parte de su tiempo de ocio a la vida en el gimnasio. En su niñez hizo ballet clásico, que abandonó después de 8 años de práctica intensiva, huyendo de la excesiva disciplina y del intenso control sobre su vida. Actualmente tiene un trabajo sedentario de administrativa y usa el gimnasio como "válvula de escape", acude a él dos veces al día, antes y después de su horario laboral. Aunque ha hecho grandes amigos en el gimnasio dice que cuando entra en éste no se dedica a hablar con sus compañeros/as sino a entrenar, y que sus mejores amistades son de fuera de este mundo. Lee mucho sobre nutrición deportiva, aunque su dieta no es especialmente estricta, 
suele salir a comer con sus amigos/as, no es amiga de los excesos y su metabolismo tiende a quemar grasas. Su cuerpo denota los efectos de quince años de gimnasio, en los que ha compaginado el trabajo con pesas con otras muchas actividades indoor, tales como pilates, artes marciales o aerobic. Compitió como culturista hace algunos años en categoría fitness, justo después de divorciarse, aunque abandonó pronto la escala competitiva, sin alcanzar grandes méritos deportivos. Una competición a la que llegó por recomendación de un compañero de gimnasio y de la que guarda un recuerdo de mucha timidez y vergüenza a la hora de exponerse por primera vez de cara al público, pero como una experiencia gratificante y hasta divertida, compartida con sus amigos/as que iban a verle a las competiciones. En su testimonio dice buscar un cuerpo atlético pero sin excesivo volumen muscular, aunque en algunas zonas de su cuerpo (como los brazos o la espalda) este sea más que evidente. No expresa haber vivido situaciones de rechazo por su conformación corporal, salvo en algunos casos de comentarios de hombres delgados que se comparaban con, para ellos, su "exceso de músculos", lo que interpreta más que como casos de incómoda intromisión como casos de manifiesta inseguridad masculina. Así nos relata su situación actual, en la que el gimnasio es un espacio de goce y liberación, de presentismo, pero también, como decimos, de construcción regeneradora:

"No tengo pareja, no tengo familia, no tengo hijos, tengo todo el tiempo libre para mí... Y lo que no me voy es a quedar en casa en el sofá. Eso sí que me da dolor de cabeza. Y me gusta este mundo... Es que yo disfruto. Yo me lo paso bien... No entiendo que a la gente no le guste el gimnasio, con tantísimas cosas que hay para hacer en un gimnasio, con tantas actividades que hay... que no te guste una... Mira, danza del vientre, yo que sé, pilates, yoga... Tu forma de ser ¿qué es? más... tranquila, pues el taichí, más de fiesta, pues el baile, o yo que sé... Algo tiene que haber que te guste. Que si esto se me acabará algún día, que tendré que bajar este ritmo... pues claro, imagínate con más años, o pariendo, o criando... yo por eso estoy haciendo todo lo que puedo, viajar todo lo que puedo, entrenar todo lo que puedo y el día que tal... ya sé que esto se me acaba. Pero bueno, con el tiempo ya se verá, ya saldrá de mí el ir quitándome de ciertas cosas...".

El cuerpo es el espacio de transformación, la herramienta de cambio, la palanca, el lugar de liberación activa de cargas, tensiones y rupturas. Pero este disfrute no implica siempre presentismo o cortoplacismo, pues se mantiene en algunos casos en estas atletas hasta edades avanzadas, cuando la experiencia artesana y, por tanto, su goce se consolidan a la par que el cuerpo, su herramienta se deteriora. Por ejemplo, en momentos en los que los hijos han crecido, los discursos se centran en el control metódico de la salud, en el autoconocimiento, pero sin dejar de fondo el norte de la musculación. El caso de Katy, una culturista veterana que se ha fogueado en competiciones desde los años 90 y que no quiere dejar de mantener su actividad, al menos a nivel aficionado, nos ilustra estos extremos:

"No he tenido nunca lesiones. La alimentación la cuido muchísimo. De hecho yo estoy ahora en proceso de menopausia... Y tal y como lo llevo yo y por lo que le oigo a mis amigas, pues se quedan flipadas... salgo a patinar... Me cuido mucho y me escucho mucho. Hago dos ciclos de complejos vitamínicos durante un mes, antes del verano y antes del invierno, me tomo mi calcio. $Y$ claro, no tengo osteoporosis, me hago analíticas para ver cómo estoy... es difícil que me resfríe... Claro, mi entrenamiento, sobre todo en la sala de pesas, me cuesta... Me cuesta no manejar los kilos que yo he manejado. Pero me cuesta no tanto porque no pueda moverlos, sino porque no debo hacerlo como hace 20 años" (mujer culturista, 48 años, 30 años de práctica, 12 de ellos compitiendo).

La observación directa en el gimnasio lleva a advertir la circunstancia de que no sólo es el músculo el identificador de masculinidad, sino también el desempeño. No puede negarse que la cantidad de peso levantado es indicador de prestigio entre los compañeros varones. Un reconocido exculturista nos relataba que trabajar sistemáticamente con sobrepeso no es trabajar bien, lo que para él significa "más que peso, pretender levantar el ego". Para el caso de las mujeres, como refieren Schilling y Bunsell (2009: 148), el culturismo se convierte en un espacio productivo en el que éstas despliegan un "exceso" de producción con respecto a la norma, a la par que de consumo. Consumo dietético, de proteínas, de calorías....pues para hacer crecer el músculo hay que trabajar y descansar, pero también hay comer por encima de la media de lo que se come. En nuestra experiencia de observación hemos comprobado que, si bien las culturistas más desarrolladas muscularmente dejan a muchos hombres atrás en cuanto a musculación y desempeño, el no tener que demostrar ambos elementos de distinción en el gimnasio les coloca en una posición privilegiada, más "prudente", al margen de excesos continuados, lo cual no solo hace sus entrenamientos más efectivos, sino que en cierta medida las protege también de las lesiones y acerca aún más al trabajo en el gimnasio al 
ejercicio de una experiencia gozosa.

"Entonces, si yo levantaba en press de banca, que llegué a levantar mis 100 kilitos, para mí estaba bastante bien. Había días en que decía 'pues no voy a poder' y si me tenía que quedar en 80 , me quedaba en 80 y no pasaba nada. O sea, que... siempre me he cuidado mucho y hasta hoy no he tenido lesiones" (mujer culturista, 52 años, 28 años de práctica).

Pese a que habitualmente se sobreentiende que, como en otros deportes actuales, la mecanización y maquinización son los principales protagonistas de los resultados e incluso de la lógica de funcionamiento, hasta el punto de poder hablar exclusivamente de fábrica de tecnocuerpos, como venimos diciendo, el culturismo requiere, en parte como producto de su impronta artesana, una claro despliegue de habilidades técnicas, estéticas y manuales. Esto se comprueba en el modo en el que los/las culturistas huyen de las cada vez más complejas máquinas de musculación conforme avanzan en el conocimiento experto de su deporte, acercándose a mancuernas y pesos libres, más simples, pero a la vez más versátiles, pues estos exigen un mejor dominio técnico para maximizar el rendimiento y evitar lesiones, adaptando el ejercicio a las exigencias personales de cada momento. Este proceso de des-maquinización recuerda el desenvolvimiento de la artesanía durante la maquinización producto de la Revolución Industrial: "a medida que la cultura mecánica maduraba, el artesano del siglo XIX se mostraba cada vez menos como mediador y más como enemigo de la máquina. Contra la perfección rigurosa de la máquina, el artesano se convertía en emblema de la individualidad humana, emblema concretamente constituido por el valor positivo que se atribuía" (Sennet 2008: 109).

Para el caso de las mujeres culturistas con más edad y experiencia, o simplemente el de las que presentan un mayor desarrollo muscular, esta reacción artesana ante el avance de la máquina, que es común en ambos sexos, se solapa con cierta rebeldía ante algunos nuevos artefactos que muestran los gimnasios. Se trata de máquinas de musculación de creciente especialización en el trabajo por grupos musculares que, según la norma generizada imperante en el ejercicio, "preocupan a las mujeres", es decir, básicamente, muslos, glúteos y caderas, dentro de la línea anteriormente señalada, situada en la cintura como línea delimitadora del espacio de trabajo entre ambos sexos. Es decir, máquinas en principio "neutras" en cuanto a su concepción, pero claramente feminizadas en cuanto a su uso. Los testimonios remarcan este hecho. Ya sea en el caso de las bromas y comentarios enunciados por los culturistas ante, por ejemplo, la máquina que trabaja los glúteos (que aquellos llamadas jocosamente "la máquina de hacer el culito brasileño" o "la máquina del culito respingón", y que pocos hombres se atreven a usar), ya sea en los propios discursos de las mujeres culturistas más desarrolladas:

"Yo desde que domino el tema, con peso libre y banca, con pesas y mancuernas hago todo el trabajo, que me dejen de maquinitas. Y después está el entrenamiento que se hace ahora, que bajo mi punto de vista, así específico para mujeres, no me sirve. Solamente se hace el tren inferior... el cuerpo es el cuerpo y la musculación es la musculación, el dedicarte solo al tren inferior y hacer muchas repeticiones y tal... vale, pero ¿y el resto del cuerpo? Es mi forma de entrenar, yo empecé con un entrenamiento que me lo enseñaron de una manera y así lo hago, y me va bien..." (mujer culturista, 48 años, 30 años de práctica, 12 de ellos compitiendo).

Por otra parte, la reelaboración de la belleza femenina también está presente, tanto en los discursos como en las prácticas. La necesidad de construir una respuesta compensatoria ante lo que se considera que "se ha perdido de feminidad" es también una constante, confirmando un estilo o estética de ultrafeminidad. Shilling y Bunsel (2009: 10) encuentran prácticas de feminización cosmética, vigilancia de la ropa, evitación de andares masculinizados, etc., todo ello en la medida en que el placer de la construcción corporal compense en el balance, pues se sobreentiende que su compromiso es con el músculo, con su afán de superación, más que con la feminidad. Sin embargo, el músculo no se sobrepone, hace concesiones a la feminidad. Como refiere una de nuestras entrevistadas: "el ser femenino no es solamente porque tengas el 90-60-90, puede ser femenino hablando, con la mirada, con gestos...."

En otros casos, como el de la siguiente culturista, que después de más de 10 años de práctica deportiva decidió abandonar esta, es precisamente el hecho de no identificarse con ese estilo estético feminizado una de las razones principales para no continuar con la práctica del culturismo. El problema surge, en estos casos, porque para contrarrestar el exceso de músculo debe adoptarse una estética ultra-feminizada (compuesta de maquillaje, peluquería, ropa, etc., pero también de ademanes y discurso que denote que se 
es muy mujer), estética que no sea acorde con los deseos, los gustos o la personalidad propia: "Yo no soy ni de ponerme las uñas así largas, ni de ponerme extensiones, ni de ir maquillada, ni de ponerme tacones, ni de ponerme minifalda. Y claro, si tú ves a una de esas mujeres culturistas en chándal, que en realidad no se dejan ver así, pero bueno, con las uñas cortas, sin pintar, ni maquillar dirías... puff...Y cuando las ves pintadas y maquilladas... a mí llamar la atención tanto, para que no se equivoquen conmigo, no me agrada... Así que controlo y tampoco llevo tanto músculo, ni tanta pintura encima para disimularlo" (mujer culturista, 37 años, 11 años de práctica, 2 en competición).

Desde una interpretación más afinada de lo dicho hasta ahora, también podría entenderse que la complejidad de la máquina se rechaza para construir una nueva máquina transformadora, formada de cuerpo y herramienta (las simples pesas, extensión del propio cuerpo), en la que el género como categoría dicotómica estaría ausente. Este cuerpo-máquina, en la línea del cyborg que propone Donna Haraway (1991: 255), sería en cierta medida lo que esta autora concibe como "una nueva criatura en un mundo postgenérico".

\subsection{Relaciones socioafectivas: endogamia, acuerdos, conflictos y sexualidad}

Una de las características básicas del culturismo, que explica también la referida predilección analítica de algunos autores por su vertiente subcultural, radica en su carácter intensivo y absorbente que se traslada a múltiples ámbitos de la vida personal, laboral y familiar. Como hemos apuntado, el lema comúnmente enunciado por cualquier culturista desde el momento que se le requiere su primer comentario sobre este deporte se resume en la sentencia "esto es un modo de vida". Se comprende así que esta práctica signifique no sólo un proyecto de transformación corporal, sino todo un proyecto vital, en la línea que propone Esteban Ruiz cuando refiere que "trabajo corporal y proyecto de vida están estrechamente unidos". Pero no existe un solo proyecto de vida, como no existe una única subcultura del culturismo.

Así, para el caso de las relaciones socioafectivas en el gimnasio, si nos referimos a las parejas "declaradamente" heterosexuales (la homosexualidad en el culturismo es aún una asignatura pendiente de estudio en profundidad, en este estudio y en la práctica generalidad de aproximaciones académicas), tales parejas son altamente endogámicas en el sentido socio-antropológico del término. De manera que puede decirse que, en el caso de parejas estables, la vía ascético-artesanal elegida es aún más gozosa cuando se experimenta por ambos integrantes de la relación. O dicho de otro modo, es menos penoso que cuando ni se comparten los códigos ni "se mira al mismo norte". Y no precisamente porque se trate de la "media naranja" que encuentra la unidad (y por tanto la propia existencia) en la otra media, como atinadamente nos propone Valcuende en su ácido ensayo sobre la heterosexualidad (Valcuende 2006: 33). Más bien las mujeres culturistas no suelen encontrar a su hombre-complemento en el culturismo, ni viceversa. Las parejas estables, por ejemplo, incorporan a su contrato no escrito la cláusula ascético-espartana del culturismo, por la cual no se ve "raro" que alguien practique un modo de vida "tan raro". Al final, se comparten los entendidos y se minimizan los malentendidos, tan comunes y fáciles de brotar en este deporte. Nuestros cuadernos de campo están plagados de anotaciones en las que encontramos, solo con respecto a la dieta, nutrida información sobre cómo en las parejas de culturistas se acuerda que el gasto en alimentación ( $y$ suplementación) sea más elevado que la media, o se sobrelleva con solvencia que el carro de la compra excluya alimentos como dulces y grasas, o se armonizan los momentos de excesos dietéticos, contados, que toda dieta rígida requiere como salida para no perder el equilibrio emocional ni social (4). Claro está que, en el lento proceso de hacerse culturista, todo esto se aprende. Así, por ejemplo, encontramos que algunos culturistas varones que quieren "sentar la cabeza" se quejan de la incomprensión no ya sólo de sus novias, sino de sus posibles familias políticas. Sobre todo de sus potenciales suegras, cuando estas insisten en compartir la comida, cualquier comida:

"Siempre pasa lo mismo. Una cosa es un día y otra que, cada vez que voy a casa de mi suegra... que '¿por qué no picas del queso?', que si '¿no te gusta la carne que he guisado...?' Y tú no sabes cómo decirle a la mujer que mi dieta es así. La hija igual lo entiende, porque se lo he explicado muchas veces... pongo la mano en el fuego que algunas madres terminan diciéndoles a sus hijas, '¿no crees que ese muchacho es un poco raro?' Y claro, así las novias te duran poco" (culturista varón, 27 años, 9 como culturista).

Este tipo de conflictos sociofamiliares asociados a la dieta es análogo al que L. Wacquant (2000: 128) encuentra entre los boxeadores que compiten. Si bien en estos, aunque la presión es importante, la 
preocupación por el peso se concentra en los momentos anteriores a la pelea, pues se permiten y, de hecho, se producen continuas excepciones y excesos. En el culturismo esta preocupación es más firme y continuada, dada la importancia capital de la dieta en la construcción muscular. Los conflictos y negociaciones abarcan toda la vida deportiva y no se terminan cuando se forma la familia, sino que se añaden retos y conflictos nuevos, como los que se extienden a los hijos, y a la familia extensa:

"Mi hijo tiene ahora 28 años, pero mi hijo no ha comido caramelos, no hay comido donuts... Porque es que no los tenía que comer. Hoy en día no es culturista, pero es una persona que es sibarita comiendo, sabe comer. Es educación, como cualquier cosa... yo he tenido con mi suegra cosillas, como cuando el niño era pequeñito y lo llevaba a casa y me decía: 'no, el niño patatas fritas y huevo', y yo le decía 'no, perdona abuela, ¿qué hay de comer?, ¿tú qué has hecho de comer?, 'brócoli', pues el niño come brócoli” (mujer culturista, 52 años, 28 años de práctica).

En el culturismo el goce está, pues, en recoger los frutos del beneficio a largo plazo del entrenamiento, de la dieta y del descanso, pues este último también modela el tiempo libre y las salidas nocturnas, por ejemplo. Beneficios que se comparten de forma variada con los que se convive, con lo cual hay que pensar que los sacrificios también. Además, como cabe comprender, incluso dentro del núcleo de entendimiento de las parejas estables, los dos cónyuges no tienen por qué llevar el mismo ritmo, ni la misma evolución en sus vidas. Así, es muy probable que las convivencias se deterioren o simplemente terminen cuando uno de los dos abandona la orientación ascético-espartana del culturismo 0 , simplemente, elija otro ritmo u otra velocidad en su proyecto de transformación corporal, como animarse a competir o dejar de hacerlo. En este sentido, es patente que la irritabilidad del competidor o competidora sea la primera queja de cualquier persona que con ellos conviva, como cualquiera que soporte estar junto a alguien que quiere llevar su rendimiento al máximo de la paciencia propia y ajena. En el culturismo esto conlleva también sumar las intervenciones radicales sobre el cuerpo: consumo de drogas o intervenciones quirúrgicas. Con respecto a estas últimas, una de las parejas de culturistas en las que ella decidió competir se rompió, como él nos confesaba, desde el momento que su "media naranja" decidió someterse a una mamoplastia, común por otra parte hoy en día en cualquier mujer culturista que quiera competir mínimamente. En otra pareja de culturistas, en la que ella compite y él no, ella nos expresaba así ese sufrimiento compartido por los dos:

"Hombre mi novio es mi entrenador, y él lo ha pasado muy mal, porque como no es competidor... Siempre me ha apoyado... pero ya cuando he estado dentro de la competición, no lo ha llevado tan bien. O sea, me ha visto mal, me ha visto de mal humor, me ha visto excesivamente delgada... me ha visto comerme el pollo sin ganas, entonces él siempre... una persona que te quiere no le gusta verte así. Bueno, luego cuando ya me he subido arriba (al escenario) y me ha visto lo que me gusta, pues ya lo ha aceptado" (mujer culturista, 26 años, 4 de práctica, 2 compitiendo).

El caso de esta otra excompetidora que tras su separación rechaza la posibilidad de volver a convivir con otro culturista competidor, es igualmente ilustrativo:

"Lo que es difícil es compartir la vida con un competidor, sea del deporte que sea. Aparte, ya no quiero una relación con una persona culturista competidor que esté metida en ese mundo... Que sea culturista o deportista sí, me gusta que a la persona le guste el deporte para compartirlo. Si lo puedo compartir mejor, pero obsesivo del gimnasio no quiero en mi vida, porque ya sé lo que es y no me apetece vivir eso" (mujer culturista, 37 años, 11 años de práctica, 2 en competición).

Con todo, entre las mujeres culturistas las consecuencias en cuanto a irritabilidad (y con ello, sus implicaciones en cuanto a la estabilidad de las relaciones socioafectivas) producidas como efectos secundarios del consumo de anabolizantes suelen ser significativamente menores que en sus compañeros varones. A ello ha contribuido, en buena medida, el referido proceso de desmuscularización que viene experimentando este deporte en su vertiente femenina desde los años 90, y las consiguientes menores exigencias en cuanto a la búsqueda de una suplementación anabolizante dirigida a las mujeres culturistas.

Finalmente, a diferencia de lo hallado por Wacquant (2000: 140) para el caso de los boxeadores de Chicago, no hemos encontrado elaboraciones significativas en términos de sanción social con respecto a la promiscuidad de los/las culturistas, ni aún al control de las relaciones sexuales. (5) En todo caso, la actividad sexual compartida se considera no pocas veces un "ajuste energético" en términos de esfuerzo aeróbico adicional que hay que compensar corrigiendo el entrenamiento del día siguiente o controlando la ingesta de 
calorías. Es común ver a jóvenes que practican el culturismo salirse de la discoteca para tomar su batido de proteínas a mitad de una noche animada para no entrar en el temido catabolismo o "pérdida muscular". Alguno incluso nos comentó la perplejidad de una chica al verle sustituir "el cigarrillo de después de" por una bebida de suplementación dietética.

Para el caso de las chicas, hasta donde ha llegado nuestro conocimiento etnográfico, los testimonios de las mujeres culturistas hablan de hombres que se fascinan por sus cuerpos musculados en situaciones de intimidad ("algunos ven músculos en una mujer y salen corriendo pero claro, otros se vuelven locos..."), por un mayor y mejor apetito y rendimiento sexual cuando se encuentran "en buena forma" y por todo lo contrario ante situaciones de stress, como es el caso de las jornadas previas a la competición, que por otra parte devienen en liberación y cierto descontrol cuando aquellas terminan. La medida del placer en estos casos viene por su contención, por su contraste con la abstinencia. Es el momento de celebración por los premios conseguidos y de cierto relajamiento y descontrol sobre las pautas dietéticas. La idiosincrasia de este deporte en el ámbito de la competición puede estar en la base de la existencia de tal abstinencia referida por los entrevistados en los días previos al evento. Pero es más lógico pensar que esta sea más consecuencia del cansancio de los días previos que origen de ella, ya que en el culturismo se invierten los términos con respecto a otros deportes: no se trata de llegar "con energías" como a un combate o a una prueba de atletismo sino, como decimos, con el músculo lo más limpio de grasa y definido posible, lo cual implica considerables niveles de deshidratación, con el consiguiente cansancio posterior. Otra cosa es lo que ocurre después de la competición, en la que el cuerpo se carga de líquidos y de energía muy rápidamente. En estos momentos sí son referidos, por ejemplo, escarceos, affaires e incluso casos de infidelidades $u$ otras relaciones extraconyugales, más comunes en casos de estancias largas o desplazamientos al extranjero, como refiere una de las culturistas entrevistadas: "yo he visto a los competidores fuera de su familia y sé como funcionan y fuera de sus parejas y veo lo que hay. $Y$ los correpasillos que hay en las habitaciones de los hoteles. Lo he vivido, entonces... sé cómo es este mundillo...". Algo que se explica en la situación de excepcionalidad de este tipo de situaciones, pero en las que, dada la presencia minoritaria de las mujeres en este deporte, cabe pensar que resulte más llamativa o "escandalosa" la participación de estas. Y también que, en consecuencia, las mujeres culturistas no competidoras recelen de su pareja competidoras, buscando formas de controlar la situación:

"Muchísimas parejas se han roto cuando él o ella ha ido a competir, porque al final es un mundo muy pequeño, te enteras de todo. Es que fulano ha estado con zutana... Cuando estuvimos en Brasil éramos un grupo muy pequeño... Y una de las que vino como juez pidió en la Federación venir a este campeonato, pues el marido venía como competidor... 'es que no me fío de ti ni un pelo'. Entonces... iba a juzgar, y a juzgarle, claro".

\section{Consideraciones finales}

"En mi opinión, uno de los próximos pasos de la antropología debería ser desarrollar habilidades visuales dentro de una ética de la mirada. Sin esta voluntariosa innovación, los antropólogos probablemente seguirán siendo incapaces de ver las múltiples y productivas formas que la belleza puede adoptar" (Linder 2007: 467).

"Tradicionalmente, la relación entre máquina y organismo ha sido de guerra fronteriza. En tal conflicto estaban en litigio los territorios de la producción, de la reproducción y de la imaginación. El presente trabajo es un canto al placer en la confusión de las fronteras y a la responsabilidad en su construcción" (Haraway 1991: 254).

Las palabras de F. Linder y de D. Haraway nos sitúan sobre la pista de uno de los principales propósitos que han guiado este trabajo: una ética de la mirada que sea capaz de advertir las formas de producción de la belleza y del placer en los procesos de reconstrucción corporal. Por ello, tal ética de la mirada no puede estar comprometida por planteamientos que sitúen las acciones de los sujetos en los estrechos márgenes de una subcultura. En esta aproximación al mundo del culturismo femenino hemos referido el hecho de que los estudios científicos sobre el culturismo en general no acaban de desprenderse de la imagen pública que comúnmente se ofrece de este deporte desde los medios de comunicación de masas. Una imagen que se resume en el estigma del descontrol, de la falta de medida: el fin narcisista se vale de cualquier medio para su consecución, por lo que aspectos como el uso de drogas, el desequilibrio emocional o la inmadurez 
mental persisten como argumentaciones que basculan entre la culpa, el pecado y la penitencia. La idea de una "subcultura del culturismo" homogénea y cosificada frente a la "normalidad cultural" es un subproducto de este panorama estigmatizador y simplificador y ha estado, y sigue estando, presente en la aprehensión de este fenómeno.

Las consecuencias del debate público que se establece sobre el cuerpo en nuestra sociedad encuentran un espacio óptimo de representación en el universo culturista. Si el culturismo en general resulta, como hemos visto, estigmatizado, la paulatina desmuscularización del culturismo femenino revela las dificultades que plantea cualquier lucha (ya sea esta declarada, explícita o implícita) contra los esquemas duales hombremujer en la percepción de los cuerpos. La importancia de la carnalidad en la construcción de una identidad sexuada (Braidotti 2005) nos ha llevado en nuestro caso, más que a ocuparnos de las posiciones y lógicas mantenidas en aquellas luchas, a revelar lo que, en la experiencia cotidiana, apunta a una dimensión dinámica y activa de la reconstrucción corporal, más allá de estrechas fronteras de corporeidad. Nos hemos centrado en la vivencia en términos de placer productivo que comporta tal reconstrucción corporal, lo que supone un pensar y vivir el cuerpo por parte de las mujeres que optan de forma continuada y estable por su musculación, desgranando algunas de sus implicaciones fenomenológicas. En esta línea, la lenta metamorfosis que supone tal reconstrucción implica un paulatino proceso de acomodación y de ajuste del cuerpo y de su percepción social, de los saberes técnicos exigidos y aprendidos, y del marco de relaciones sociales mantenido dentro y fuera del gimnasio. Como toda metamorfosis, esta también comporta dolor. Un dolor en delgada frontera con el placer (por lo conseguido, por lo experimentado, por la vivencia de autocontrol, por saberse parte de un proyecto...) y que exige también cierta separación del mundo, en el ejercicio de una opción ascético-espartana.

Implicaciones regeneradoras, reproductivas, usan el cuerpo como herramienta de cambio, de palanca. En las vivencias y testimonios de estas mujeres se desprende que el gimnasio pasa de ser un espacio exclusivamente de seguimiento acrítico de las normas sociales a ser un santuario de liberación de stress, de endorfinas, de sufrimiento y también de canalización de la tensión que esta sociedad ejerce sobre el control de los cuerpos. Una experiencia gozosa que se consolida con el paso del tiempo y, en la medida que supone la adquisición de saberes y técnicas, comporta también autoconocimiento y reconocimiento social. También en lo que implica el ejercicio del control sobre el tecnocuerpo a través del desempeño artesano. Este ejercicio artesano también ayuda a afrontar, en cierta medida, la rigidez en el sistema sexo-género que está presente, como hemos visto, desde el diseño estructural de los gimnasios hasta el sistema de relaciones dentro y fuera de ellos, pasando por la configuración aparentemente neutra, maquinal, pero fuertemente generizada de los propios aparatos y máquinas.

La heteronormatividad sexual planteada por las prácticas de las mujeres culturistas es una primera de las primeras evidencias que se obtienen del análisis de este deporte, pero sus prácticas no sólo se dirigen a este cuestionamiento. Surge aquí un apasionante abanico exegético: el sobrecumplimiento de lógicas deportivas, la falta de exposición narcisista pese a lo que parece evidente, la construcción de un tercer o cuarto género o, si se prefiere, la deconstrucción del sistema de sexo-género, la maquinización y sus readaptaciones, la concepción del deporte como espacio de autoevocación y reconstrucción personal... que no son matices a la cuestión general, sino vías analíticas a ser exploradas en profundidad en posteriores estudios y que esperamos que este trabajo pueda alentar, en cierta medida, a ello.

En suma, uno de los empeños de este trabajo ha sido tratar de abordar un campo de estudio que, en su diversidad y complejidad, presenta perfiles difícilmente aprehensibles. Mediante esta aproximación etnográfica hemos pretendido poner sobre la mesa dificultades interpretativas de partida que nacen, cuando no de la fuerza de los estereotipos y estigmas, al menos del desenfoque o escasa profundización en las experiencias, expectativas y contradicciones de los sujetos analizados. Hemos intentado así aportar alguna luz en un campo tan sobresimplificado y estereotipado como el culturismo y aún más, en particular, el culturismo femenino, afectado por rígidas construcciones dicotómicas de sexo-género. Abordando cuestiones de este campo como el goce, la belleza o las relaciones interpersonales en el seno de estos proyectos de transformación corporal ubicados en las fronteras de las reglas de género, contribuimos también a presentar algunas de las contradicciones presentes en nuestras sociedades con respecto a las representaciones sobre el cuerpo, el ejercicio físico y la feminidad. En concreto, a pesar de los estrechos márgenes que socialmente se permiten para la (re)construcción de los cuerpos, es posible la existencia de construcciones creativas y el desarrollo de potencialidades productivas artesanales, transformadoras del cuerpo como herramienta y producto a la vez, pero sobre todo como lugar de interpelación. 


\section{Notas}

1. En este sentido, es preciso aclarar que aunque en este artículo hacemos uso del término "culturismo femenino", en lo que se entiende estrictamente como tal dentro de las estructuras federativas que regulan este deporte en España y, por tanto, en cuanto a competiciones en territorio nacional, presenta una actividad mínima, concentrándose dichas competiciones en categorías en las cuales, a priori, se exige un menor grado de musculación. Dichas categorías son contempladas bajo las denominaciones bodyfitness, phisic femenino y bikini, estas dos últimas de muy reciente implantación. El estudio de las controversias sobre este proceso de desmuscularización del culturismo femenino y sus implicaciones sociales y micropolíticas, en parte abordadas en el trabajo de Tanya Bunsell, Strong and Hard Women: an Ethnography of Female Body Building (Bunsell 2013: 34), quedan por motivos de espacio fuera de los contenidos de este artículo.

2. El estudio se ha realizado en dos fases: la primera de ellas (2005-2007) financiada por la Dirección General de Drogas y Adicciones de la Junta de Andalucía, se incardinó en un proyecto de investigación dirigido por la antropóloga Carmen Mozo y centrado en el estudio de la vigorexia en población culturista masculina. La segunda fase (2011-2013), sin financiación específica, se ha concentrado en el estudio del "culturismo femenino".

3. A partir de datos extraídos de las competiciones oficiales de los últimos años, puede estimarse en un $10 \%$ el número de mujeres que compiten en España en la modalidad más cercana en grado de muscularización a lo que antes se llamaba culturismo (es decir en la referida categoría bodyfitness) con respecto al total de culturistas (hombres y mujeres). Ello significa un total de unas 50 mujeres en toda España, lo que cual es una cifra ínfima en comparación con las 1.500 licencias de competición que se estiman para ambos sexos (Fuente: IFBB, 2014).

4. Los manuales de culturismo avanzado hablan más de nutrición que de sistemas de entrenamiento y, como cabe esperar, no son sólo técnicos sino que también refuerzan el sistema de creencias del culturismo. Así, en uno de los más populares, puede leerse: "Disfrute de un día libre. Adherirse a una dieta requiere disciplina. Con todas las opciones que hay aquí, restringir su consumo puede dar lugar a ansiedad, la cual le puede volver irritable. Con esto en mente, le concedo permiso para aliviar el régimen con un poco de holgura. En su día libre, usted puede comer lo que quiera. Sea niño en una tienda de dulces. Elimine la ansiedad fuera de su sistema de alimentación. (...) Usted puede elegir un domingo, o un día que coincida con un acontecimiento social en particular, como una fiesta, cumpleaños, o cualquier otra reunión. Cualquier día que escoja, saque el máximo provecho de él. No le hará daño un día a la semana -es la disciplina en la dieta a largo plazo la que cuenta" (Evans 2004: 39. Hay edición en español: Programas de musculación. Ediciones Tutor. Madrid, 2011. Las cursivas son nuestras).

5. En Jordi 2013 desarrollamos una aproximación al análisis de la sexualidad en los gimnasios en general y en el deporte del culturismo en particular.

\section{Bibliografía}

Bornstein, Kate

1995 Gender outlaw. New York, Vintage.

Braidotti, Rosi

2005 Metamorfosis. Hacia una teoría materialista del devenir. Madrid, Akal.

Bunsell, Tanya

2013 Strong and Hard Women: an Ethnography of Female Body Building. Milton Park, Abingdon, Oxon, 
Routledge.

Brace-Govan, Jan

2004 "Weighty matters: Control of women's access to physical strength", The Sociological Review, $n^{\circ} 52$ (4): 503-531.

DOl: 10.1111/j.1467-954X.2004.00493

Castelnuovo, Shirley y Guthrie, Steph

1998 Feminism and the female body: Liberating the Amazon within. Londres, Lynne Rienner.

Connell, Raewyn

1995 Masculinidades. México, Programa Universitario de Estudios de Género, Universidad Nacional Autónoma de México, 2003.

Chananie-Hill, Ruth A. (y otros)

2012 "Deviant or Normal? Female Bodybuilders' Accounts of Social Reactions", Deviant Behavior, $\mathrm{n}^{\circ} 33$ (10), 811-830.

DOl: $10.1080 / 01639625.2011 .647592$

Esteban, Mari Luz

2004 Antropología del cuerpo. Género, itinerarios corporales, identidad y cambio. Barcelona, Edicions Bellaterra.

Evans, Nick

2004 Men's Body Sculpting. Human Kinetics.

Goffman, Ervin

1963 Estigma. La identidad deteriorada. Buenos Aires, Amorrortu, 2003.

1983 "The interaction order". American sociological review, n 48: 1-17.

Gracia, Mabel

2010 "(Des)encuentros entre comida, cuerpo y género", en Javier Eloy Martínez Guirao y Anastasia Téllez Infantes (eds.), Cuerpo y cultura. Barcelona, Icaria: 79-107.

Grogan, Sarah (y otros)

2004 "Femininity and muscularity: Accounts of seven women body builders", Journal of Gender Studies, $\mathrm{n}^{\circ}$ 13 (1): 49-61.

Haraway, Donna J.

1991 Ciencia, cyborgs y mujeres: la reinvención de la naturaleza. Madrid, Ediciones Cátedra. Universidad de Valencia. Instituto de la Mujer, 1995.

Hughes, Robert y (Jay Coakley)

1991 "Positive Deviance Among Athletes: The Implications of Overconforming to the Sport Ethic", Sociology of Sport Journal, n 8: 307-25.

Jordi, Mario

2011 "La vigorexia: un viaje a los límites del tecnocuerpo", Actas del XII Congreso de Antropología, León, FAAEE y AACL: 1273-1282. [En cd-rom].

2013 "El músculo en el centro: masculinidades en los gimnasios contemporáneos", en José María Valcuende del Río, María José Marco Macarro y David Alarcón Rubio (coords.), Estudios sobre diversidad sexual en Iberoamérica. Sevilla, Aconcagua: 321-334.

Kane, Marie Jo

1995 "Resistance/transformation of the oppositional binary: Exposing sport as a continuum", Journal of Sport and Social Issues, nº 19 (2): 191-218. 
Klein, Alan M.

1992 "Man Makes Himself': Self-objectification and Alienation in Bodybuilding Subculture", Play and Culture, $\mathrm{n}^{\circ} 14$ (4): 326-337.

1993 Little Big Men. Bodybuilding Subculture and Gender Construction. Albany, State University of New York Press.

Lowe, Maria R.

1998 Women of steel: female bodybuilders and the struggle for self-definition. New York, New York University Press.

Linder, Fletcher

2007 "Life as art, and seeing the promise of big bodies", American Ethnologist, n 34 (3): 451-472.

Marcos, Javier

2008 "El observador y lo exótico cotidiano. Unidades de análisis y el estudio de nuestra cambiante y plural realidad sociocultural", Gazeta de Antropología, 2008, nº 24 (2).

http://hdl.handle.net/10481/6964

Mauss, Marcel

1934 "Techniques of the body", Economy and society, n² 2 (1): 70-88.

Monaghan, Lee F.

2001 "Looking good, feeling good: The embodied pleasures of vibrant physicality", Sociology of Health \& IIIness, $\mathrm{n}^{\circ} 23$ (3): 330-356.

Roth, Amanda (y Susan A. Basow)

2004 Femininity, Sports, and Feminism: Developing a Theory of Physical Liberation, Journal of Sport and Social Issues, $n^{\circ} 28$ (3): 245-265. DOl: 10.1177/0193723504266990

Roussel, Peggy (y Jean Griffet)

2000 "The path chosen by female bodybuilders: A tentative interpretation", Sociology of Sport Journal, n 17 : $130-150$.

Roussel, Peggy (y otros)

2010 "The metamorphosis of female bodybuilders: Judging a paroxysmal body?", International Review For The Sociology Of Sport, nº 45 (1): 103-109. DOl:10.1177/1012690209353371

Sennet, Richard

2008 El artesano. Anagrama, Barcelona, 2009.

Shea, B. Christine

2001 "The paradox of pumping iron: female bodybuilding as resistance and compliance", Women \& Language, $\mathrm{n}^{\circ} 24:$ 42-46.

Schilling, Chris (y Tania Bunsel)

2009 "The female bodybuilder as a gender outlaw", Qualitative Research in Sport and Exercise, $\mathrm{n}^{\circ} 1$ (2): 141-159. DOl: 10.1080/19398440902909009

Shippert, Claudia

2007 "Can Muscles be Queer? Reconsidering the Transgressive Hyper-built Body", Journal Of Gender Studies, $\mathrm{n}^{\circ} 16$ (2): 155-171. DOl:10.1080/09589230701324702

Valcuende, José María

2006 "De la heterosexualidad a la ciudadanía", AIBR, Revista de Antropología Iberoamericana, $\mathrm{n}^{\circ} 1$ (1): $125-142$.

Wacquant, Loïc

2000 Entre las cuerdas. Cuadernos de un aprendiz de boxeador. Madrid, Alianza, 2004. 
